\section{Population growth}

SIR - The literature, both popular and specialist, often refers to population growth rates as exponential. More often than not this implies merely a rapid rate of increase and not necessarily its proper meaning of a fixed proportional increase in a set timespan. For example, reference to almost any long-term demographic time series shows that the expansion is not truly exponential as it does not result in a straight line on a graph of the logarithm of population against time.

Now let us explore an alternative expansion rate - according to the cube of time since the modern nation was born. Australia is a nation for which the demographic record is known fairly precisely for the non-aboriginal population since its birth in the $1780 \mathrm{~s}$, about 200 years ago. There is thus very little flexibility to be tolerated on the birth date of the nation and retrospective analysis

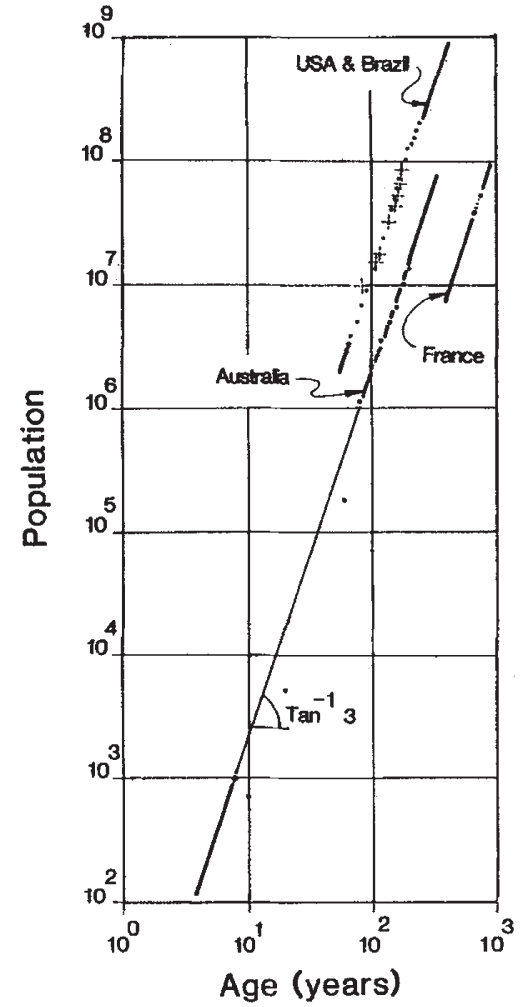

leads to the initial date of 1780 from the application of this hypothesis to Australian population data ${ }^{1}$. In fact, that population generated from the "dumping" there a few years later of several hundred largely undesirable British citizens. The relation shown in the figure for Australia exhibits a general slope of gradient 3, that is, it represents an expansion according to the cube of time on this double logarithmic plot. The only anomalies are in the very early years when the embryonic settlement was subject to reduction by disease in the exotic environment and in the mid-nineteenth century when a gold rush generated an unnatural influx.
Encouraged by the well-documented Australian example, we might explore others. The figure shows similar relations for data from France ${ }^{2}$, United States ${ }^{3}$ and Brazil $^{4}$ from which it can be concluded that these nations began in the sense of a modern society in 1233, 1724 and 1783 respectively. Historians may care to comment on events that could justify that conclusion.

In the meantime, it seems appropriate to draw attention to the far more accurate demographic projections available from this model than from the variably timedependent exponential expansion models commonly found in the literature. The reader can test this conclusion by

\section{Viscosity, noses and IQ}

SIR - P.M. Gaylarde's assertion (Nature $313,425 ; 1985)$ that I speculated "that the shape of a person's nose determines his IQ" is both of fensive and inaccurate. In fact, what Gaylarde interpreted as an "attempt to establish spurious grounds for white supremacy" in a manner "as unsavoury as those...used to justify the extermination of Jews and Gypsies in Hitler's Germany", was, both in intent and content, exactly the opposite. I urge readers who saw only Gaylarde's response to read what I wrote before passing judgement (Nature 311, 515; 1984).

It is true, as Gaylarde states, that "the viscosity of moist air is less than that of dry air", but the relevant comparison is between the cool dry air of temperate zones and the hot humid air of the tropics. Unlike liquids, gases gain viscosity with increases in temperature, and that gain more than offsets the reduction from increased humidity. For example, air going from 0 to $40^{\circ} \mathrm{C}$ and simultaneously from dry to saturated (maximizing the effect of humidity), gains about 20 micropoises of viscosity as a result of increased temperature $^{1}$ while it loses about two micropoises of viscosity from increased humidity ${ }^{2}-$ a net gain of 18 . Gaylarde is also wrong to think that nose shape, length and hairiness have little effect on airway resistance ${ }^{3}$. If the length of a tube is doubled, pressure must be increased twofold to maintain constant flow, and if the radius of a tube is halved, pressure must be increased an additional sixteenfold to maintain flow a 32 -fold increase. Add the fact that saturated hot air (say $40^{\circ} \mathrm{C}$ ) contains less oxygen (about 7 per cent less), and one can begin to appreciate the value of a short wide hairless nose in hot humid climates.

But the brunt of my nose argument, the entirety of which was not essential to my point, was that it might be disadvantageous not to have a dust-trapping nose in dusty environments. In support of this speculation I pointed out that "among American racial and ethnic groups, only exploring, say, the 50 -year forecasts that would have been made at decadal intervals over the past century or so using both this cubic expansion and any exponential model. The results are most encouraging and promise much for demographic planning.

56 Sydney Grove,

S.M. DAVIDSON

\section{Sunholme,}

Wallsend,

Tyne and Wear

1. Cameron, R.J. Official Yearbook of Austratia Vol, 61, 135 (Australian Bureau of Statistics, Canberra, 1976).

2. Annuaire Statistique de la France Vol. 88, 25 (Institut

National de la Statistique et des Etudes Economiques, Paris, 1983)

. Teir, J.E. et al. Statistical Abstracts of the United States Vol 100, 6 (US Government Printing Office, Washington DC, 1979).

Anuario Estatistico do Brasil, 39 (Instituto Brasileiro de Estatistica, Rio de Janeiro, 1971). blacks and non-Japanese orientals have a conspicuous prevalence of lung disease". I agree with Gaylarde that lung disease "is related to socioeconomic factors", but its relative inconspicuousness in hispanics leaves my point intact.

The objective of my contribution was to explain the fact that heritable differences in IQ need not be attributed to differences in "IQ genes", and I have argued that any heritable difference in IQ between races is especially unlikely to be caused by such genes $^{4}$. My point was that adaptations taken out of their evolutionary context (such as pale thin skin and long, thin, hairy noses in the tropics) are liable to be disadvantageous and could have an incidental effect on IQ. I pleaded that such questions should be investigated because "there are many factors that something could be done about if we knew what they were", for example, "people with non-dust-trapping noses can have humidifiers in their homes during the winter and take care to wear a dust-mask when doing a dusty job'. And I lamented the fact that "looking for genetic differences that incidentally affect IQ is politically unacceptable". Gaylarde has proven me right in this last regard.

Misrepresentation of facts, misreading, an astounding failure to comprehend and knee-jerk reply aside, as the son and nephew of men who fought against Hitler's Germany, and as one who grew up in a home where racists, anti-semites and fascists were clearly "the enemy", I resent Gaylarde's ludicrous insinuations.

JOHN HARTUNG

Department of Anesthesiology,

State University of New York,

Downstate Medical Center,

450 Clarkson Avenue,

Brooklyn, New York 11203, USA

Weast, R.C. Hondbook of Chemistry and Physics F-39 (CRC, Cleveland, 1965).

2. Kestin, J. \& Whitelaw, J.H. Humidity and Moisture Vol. III, 301 (Reinhold, New York, 1965).

3. Negus, Z. The comparative anatomy and physiology of the nose and perinasal sinuses (Livingstone, London, 1958). 4. Hartung, J. Curr. Anthropol. 21, 131-132 (1980). 